\title{
MEIO DE CULTURA E TIPO DE EXPLANTE NO ESTABELECIMENTO IN VITRO DE ESPÉCIES DE MARACUJAZEIRO $\left({ }^{1}\right)$
}

\author{
GLÁUCIA AMORIM FARIA $\left({ }^{2}\right)$; MARIA ANGÉLICA PEREIRA DE CARVALHO COSTA $\left({ }^{3}{ }^{*}\right)$; \\ CARLOS ALBERTO DA SILVA LEDO $\left({ }^{4}\right)$; TATIANA GÓES JUNGHANS $\left({ }^{4}\right)$; \\ ANTÔNIO DA SILVA SOUZA $\left({ }^{4}\right) ;$ MARIO AUGUSTO PINTO DA CUNHA $\left({ }^{4}\right)$
}

\begin{abstract}
RESUMO
O Brasil é um dos principais centros de dispersão da variabilidade genética do gênero Passiflora. Sua auto-incompatibilidade aliada à incidência de doenças do sistema radicular e da parte aérea, desmatamentos e monocultivos promovem perda de material genético. Tendo-se em vista o risco de erosão genética, torna-se necessário a conservação da variabilidade em bancos de germoplasma, de grande interesse no melhoramento de plantas. Estudos em relação ao tipo de explante e concentração dos meios de cultivo são necessários para se determinar protocolo de estabelecimento e conservação in vitro de germoplasma de maracujá. O objetivo deste trabalho foi avaliar a influência da concentração dos sais e nutrientes do meio MS e tipos de explantes no estabelecimento e crescimento das espécies de maracujazeiro Passiflora giberti N. E. Brown, P. edulis Sims e P. laurifolia L. Em cada espécie de Passiflora havia características próprias quanto ao desenvolvimento in vitro. O meio de cultura MS completo e os segmentos nodais que continham a segunda gema axilar tiveram melhores resultados em relação às demais.
\end{abstract}

Palavras-chave: Passiflora spp., posição da gema, micropropagação.

\section{ABSTRACT \\ CULTURE MEDIUM AND TYPE OF EXPLANT IN THE IN VITRO ESTABLISHMENT OF PASSION FRUIT SPECIES}

Brazil is one of the main centers of genetic variability dispersion of the Passiflora genera. Its self incompatibility as well as disease incidence in its leaves and root system and, deforestation and monocultivation, promote loss of genetic material. Considering the risk of genetic erosion, the conservation of the variability in germplasm banks, which is of great interest in plant breeding, is necessary. Studies regarding the type of explant and concentration of the culture media are necessary in order to determine protocols of establishment and in vitro conservation of passion-fruit germplasm. The objective of the present work was to evaluate the influence of the salt and nutrient concentration in the MS culture medium and types of explants in the establishment and growth of the Passion fruit species: Passiflora giberti N. E.Brown, P. edulis Sims and P. laurifolia L. Each Passiflora species presented its own characteristics regarding in vitro development. The complete MS medium and nodal segments the second axilliary bud promoted better development of the genotypes studied.

Key words: Passiflora spp., bud position, micropropagation.

$\left.{ }^{1}\right)$ Recebido para publicação em 16 de novembro de 2005 e aceito em 23 de abril de 2007.

$\left({ }^{2}\right)$ Faculdade de Ciência e Tecnologia Albert Einstein, Cruz das Almas (BA). Doutoranda em Agronomia da FEIS/UNESP, Av. Brasil, 56, 15385-000. Ilha Solteira (SP). E-mail: glauciaamorim@yahoo.com.br

$\left({ }^{3}\right)$ Centro de Ciências Agrárias, Biológicas e Ambientais da UFRB, 44380-000, Cruz das Almas (BA). E-mail: mapcosta@ufba.br $\left({ }^{*}\right)$ Autora correspondente.

$\left({ }^{4}\right)$ Embrapa Mandioca e Fruticultura Tropical, 44380-000, Cruz das Almas (BA). E-mail: ledo@cnpmf.embrapa.br, tatiana@cnpmf.embrapa.br, assouza@cnpmf.embrapa.br, maugusto@cnpmf.embrapa.br 


\section{INTRODUÇÃO}

A cultura do maracujazeiro possui significativa participação no mercado nacional. A evolução da produção do maracujá-amarelo (Passiflora edulis Sims f. flavicarpa Deg.) possibilitou ao Brasil se destacar como maior produtor mundial. Entretanto, a produtividade nacional ainda é baixa, cerca de 14 t.ha ${ }^{-1}$ ano $^{-1}$ (IBGE, 2006), devido a problemas fitossanitários, técnicas inadequadas de cultivo e ausência do uso de cultivares superiores.

A adoção de híbridos horticulturais resistentes e tolerantes a moléstias, bem como o uso de porta-enxertos resistentes podem solucionar os problemas de produção. As espécies P. laurifolia L., P. edulis Sims f. edulis e P. giberti N. E. Brown podem ser promissoras para futuros trabalhos de melhoramento, quer pela criação de híbridos, quer por meio da utilização como porta-enxertos de maracujáamarelo.

Apesar de grande potencial morfogenético das espécies de Passiflora, até o momento, resultados concretos em termos de eficiência de protocolos de estabelecimento, desenvolvimento, regeneração e conservação in vitro não foram obtidos para a maioria das espécies. Alguns fatores têm contribuído para isso, dentre eles a variação da resposta entre genótipos, principalmente quando são utilizadas espécies selvagens, não cultivadas, que possuem grande variabilidade genética.

Uma vez que as diversas espécies de maracujazeiro respondem diferentemente a estímulos visando à indução da morfogênese, para o planejamento de experimentos que visem à conservação in vitro de germoplasma deve-se conhecer a via de regeneração (organogênese ou embriogênese somática), a região do explante que responde ao estímulo e a presença ou ausência de calo.

A organogênese in vitro pode ser definida como o processo pelo qual células e tecidos vegetais são induzidos a sofrer mudanças que levam à produção de uma estrutura unipolar, denominada primórdio vegetativo ou radicular, cujo sistema vascular está freqüentemente conectado com o tecido de origem. Pode ocorrer diretamente a partir de células do explante original ou, indiretamente, via formação de calos. Na embriogênese são obtidos embriões somáticos, caracterizados como estruturas bipolares não conectadas ao explante pela vascularização (Grattapaglia e Machado, 1998).

Diferentes tipos de explantes podem ser utilizados para iniciar o cultivo in vitro. Alguns autores relatam o cultivo in vitro de espécies de maracujá, utilizando como explantes segmentos nodais e internodais (KANTHARAJAH e DODD, 1990; DREW, 1991; FARIA e SEgURA 1997); gemas apicais (SCORZA e Janick, 1980; Drew, 1991; Faria e Segura, 1997; JunGHANS et al., 2002), protoplastos (Dornelas, 1995; Отоnі et al., 1996); primórdios de brotos (KAWATA et al., 1995) e discos foliares (MONTEIRO-HARA, 2000).

A grande maioria dos trabalhos de cultivo in vitro de Passiflora foi realizada com $P$. edulis Sims f. edulis e $P$. edulis f. flavicarpa com ênfase à indução e multiplicação de gemas através de segmentos nodais, internodais e discos foliares (MONTEIRO-HARA, 2000). Recentemente, segundo TAKAHAshi (2002), a organogênese tem sido relatada para as espécies $P$. amethysthina, $P$. giberti N. E. Brown, P. incarnata, $P$. maliformis, $P$. molissima, P. nitida, P. quadrangularis e P. suberosa.

A micropropagação em Passifloraceae tem sido descrita por Moran Robles (1978), KantharajaH e Dodd (1990), Drew (1991), KaWATA et al. (1995) e GiLl et al. (2003), sendo a grande maioria dos trabalhos realizada com $P$. edulis e $P$. edulis f. flavicarpa. Inclusive Freitas (1997) considera que a micropropagação oferece uma boa alternativa para essa cultura, pois podem ser produzidos, em grande escala, clones selecionados de variedades com interesse comercial, a exemplo das espécies citadas anteriormente.

Em geral, o tipo de explante mais utilizado na micropropagação do maracujazeiro são os segmentos nodais (Kantharajah e Dodd, 1990; Drew, 1991; KaWATA et al., 1995; FARIA e SEgUra 1997) e ápices caulinares (FARIA e SEgURA, 1997; JungHANS et al., 2002). A grande vantagem desse tipo de explante é que por envolver órgãos meristemáticos pré-formados, propicia maior estabilidade genética das plantas micropropagadas.

A regeneração de plantas in vitro a partir de outros tipos de explante, tais como cotilédone, disco foliar, hipocótilo, também pode ser utilizada para a micropropagação, desde que a morfogênese ocorra por organogênese ou embriogênese somática de forma direta, ou seja, sem que ocorra a formação de calo, evitando assim a ocorrência de variantes somaclonais. Essa característica, apesar de desejável para trabalhos de melhoramento, é extremamente prejudicial quando da conservação e multiplicação clonal, pois a estabilidade genética deve ser mantida.

DORNELAS e VIEIRA (1994) foram os primeiros a descreverem a regeneração de plantas em espécies de Passiflora por meio da organogênese direta, utilizando como explante cotilédone, hipocótilo e segmento foliar.

Este trabalho teve como objetivo avaliar a influência de meios de cultura e tipos de explantes 
no estabelecimento e crescimento das espécies de maracujazeiro Passiflora giberti N. E. Brown, P. edulis Sims f. edulis e P. laurifolia L.

\section{MATERIAL E MÉTODOS}

O experimento foi desenvolvido em laboratório no período de fevereiro a julho de 2003. Para este estudo foram utilizados os acessos caracterizados de Passiflora giberti N.E. Brown, P. edulis Sims f. edulis e P. laurifolia L. do Banco Ativo de Germoplasma de Maracujá da Embrapa Mandioca e Fruticultura Tropical em Cruz das Almas (BA).

As sementes dessas espécies, oriundas de polinização controlada, foram levadas à casa de vegetação, semeadas para germinação em sacos de polietileno de $10 \times 25 \mathrm{~cm}$, utilizando a mistura terra e esterco de curral na proporção 3:1, tomando-se os devidos cuidados fitossanitários com a qualidade das sementes, preparo do substrato, semeadura e manejo das mudas.

Ainda em casa de vegetação, após os 60 dias de plantio, as plantas foram cortadas após a quarta gema axilar em relação ao ápice e levadas ao laboratório de cultura de tecidos onde foram desinfestadas com etanol $70 \%$ por 40 segundos e solução de hipoclorito de sódio $(\mathrm{NaOCl}) 0,2 \%$ por 15 minutos, e, em seguida, lavadas com água destilada esterilizada por quatro vezes.

Para o estabelecimento in vitro foram utilizadas microestacas com aproximadamente $1 \mathrm{~cm}$ de comprimento, contendo a gema apical ou gemas axilares. Os explantes foram cultivados em magentasâ com $30 \mathrm{~mL}$ do meio MS (Murashige e SKoog, 1962) e com a metade das concentrações dos sais minerais e vitaminas, MS e 1/2MS, respectivamente, suplementados com $30 \mathrm{gL}^{-1}$ de sacarose e $2 \mathrm{gL}^{-1}$ de phytagelâ, ajustado a um $\mathrm{pH}$ de 5,8 , autoclavado a $121{ }^{\circ} \mathrm{C}\left(1 \mathrm{~kg} \mathrm{~m}^{-2}\right)$ e sem adição de regulador de crescimento. O cultivo foi realizado sob condições de fotoperíodo de 16 horas, temperatura de $27 \pm 1{ }^{\circ} \mathrm{C}$ e densidade de fluxo de fótons $22 \mathrm{mE} \mathrm{m}^{-2} \mathrm{~s}^{-1}$.

Foi utilizado o delineamento inteiramente casualizado, com 25 repetições, no esquema fatorial 3' 2' 4, três espécies (P. edulis Sims f. edulis, P. giberti N. E. Brown e P. laurifolia L.), duas concentrações de sais do meio de cultura (MS e $1 / 2$ MS) e quatro tipos de explantes em função das posições das gemas (gema apical, $1 .^{\text {a }}$ gema axilar, $2 .^{\text {a }}$ gema axilar e $3 .^{\text {a }}$ gema axilar), perfazendo um total de 24 tratamentos. A parcela experimental foi representada por uma magentaâ contendo um explante. As avaliações foram realizadas aos 45, 75 e 105 dias após a incubação dos explantes em meio de cultura, sem subcultivos.
Avaliaram-se comprimento das brotações, em cm, número de raízes, número de folhas e coloração das folhas. Para esta última variável foi atribuída a seguinte escala de notas: 1- folhas totalmente verdes; 2 - folhas verde-claras e 3-folhas amareladas (início da senescência). Os dados foram submetidos à análise de variância considerando o delineamento inteiramente casualizado no esquema de parcela subdividida no tempo. As médias dos tratamentos foram comparadas pelo teste de Tukey a $5 \%$ de probabilidade. A variável - comprimento das brotações - foi transformada para ln $(x+10)$ e as variáveis - número de folhas e coloração da folha - foram transformadas para raiz $(\mathrm{x}$ $+0,5)$ visando ao atendimento das pressuposições da análise de variância. As análises foram realizadas utilizando o programa SAS - Statistical Analysis System (SAs Institute, 2000).

\section{RESULTADOS E DISCUSSÃO}

Por meio de observações visuais, verificou-se a conversão dos explantes em microplantas, independentemente da espécie e da concentração do meio de cultura. Em nenhum dos tratamentos foi observada a oxidação dos explantes.

Houve $100 \%$ de contaminação bacteriana endofítica dos explantes com a $4 .^{\mathrm{a}}$ gema axilar; razão pela qual este tratamento não foi computado nas análises estatísticas (Figura 1). De modo geral, o grau de contaminação foi crescente à medida que a posição da gema se distanciava do ápice. As maiores contaminações foram detectadas nos segmentos nodais que continham a $2 .^{a}$ e $3 .^{a}$ gemas axilares respectivamente. A menor percentagem de contaminação dos explantes excisados das posições mais próximas da gema apical pode ser explicada, provavelmente, devido a presença de conexões plasmodesmáticas em dimensões diminutas nestas células e o ritmo ativo de divisões celulares nesta região, promovendo baixa concentração de bactérias nestas células (ToRres et al., 1998).

Os resultados revelam considerável variação no comprimento das brotações, número de raízes, bem como no número e coloração das folhas. Diferenças significativas foram observadas entre espécies, concentração do meio de cultura, tipo de explante e período de avaliação. Para coloração das folhas todas as fontes de variação foram significantes $(P \leq 0,05)$. As variáveis: comprimento das brotações, número de raízes e coloração da folha tiveram CV de 2,38\%, 26,21\% e $10,09 \%$ respectivamente. Para o número de folhas foi obtido alto valor do C.V., 124,43\%, devido à discrepância entre as observações de um mesmo tratamento, característica inerente à variável em estudo (Tabela 1). 


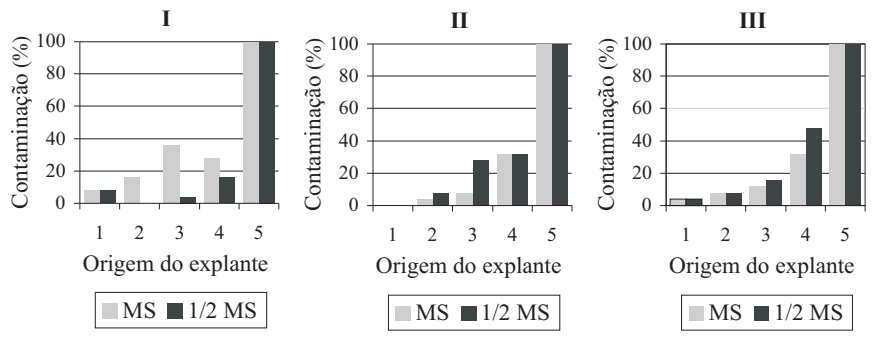

Figura 1. Porcentagem de contaminação das espécies $P$. edulis Sims f. edulis (I), P. giberti N. E. Brown (II) e P. laurifolia L. (III) em função da origem do explante e da concentração de sais do meio de cultura. 1 - gema apical; 2 - 1 . $^{\mathrm{a}}$ gema axilar; 3 - 2. ${ }^{\mathrm{a}}$ gema axilar; $4-3$. $^{\mathrm{a}}$ gema axilar e $5-4 .^{\text {a }}$ gema axilar.

Observa-se um comportamento diferenciado entre os genótipos estudados com relação ao comprimento das brotações. $\mathrm{O}$ valor mais elevado para comprimento das brotações $(2,45 \mathrm{~cm})$ foi verificado para espécie $P$. giberti N. E. Brown, diferindo significativamente do P. edulis Sims f. edulis e P. laurifolia L. Considerando as concentrações do meio de cultura, o MS completo sustentou o maior desenvolvimento das brotações, exceto para a espécie Passiflora edulis Sims f. edulis em que não foi verificada diferença significativa em relação às duas concentrações de sais do meio (Tabela 2). Portanto os resultados revelaram que o comportamento in vitro foi diferenciado entre as espécies. Resultados semelhantes foram relatados por Guzzo et al. (2004), ao verificarem que embriões de $P$. apetala, $P$. candida, $P$. coriacea, $P$. subrotunda, $P$. mayarum e $P$. morifolia germinaram em meio MS e não houve nenhum sinal de desenvolvimento no meio de cultura B5. IsUTSA (2004), avaliando o estabelecimento e desenvolvimento de $P$. edulis f. flavicarpa e P. edulis Sims f. edulis em meio de cultura MS verificou que $P$. edulis f. flavicarpa conseguiu melhor desenvolvimento, enraizamento e maior grau de sobrevivência no processo de micropropagação.

O suprimento dos nutrientes minerais no meio de cultura é essencial para sistemas de cultivo in vitro, variando conforme a espécie vegetal e o processo de cultivo (Monteiro-Hara, 2000). O meio MS é utilizado com sucesso na regeneração de microplantas para a maioria das espécies. KANTHARAJAH e DODD (1990) e KAWATA et al. (1995) obtiveram melhores respostas para desenvolvimento e multiplicação de gemas caulinares da espécie $P$. edulis Sims f. edulis em meio MS suplementado com $0,23 \mathrm{mg} \mathrm{L}^{-1}$ de BAP e $0,20 \mathrm{mg}$ $\mathrm{L}^{-1}$ de AiB. Faria e Segura (1997) regeneraram e enraizaram com sucesso microplantas, a partir de gemas axilares da espécie $P$. edulis f. flavicarpa em meio MS na ausência de reguladores de crescimento.

Tabela 1. Resumo da análise de variância para comprimento das brotações (CB), em cm, número de raízes (NR), número de folhas (NF) e coloração da folha (CF), das espécies P. edulis Sims f. edulis, P. giberti N. E. Brown e P. laurifolia L.

\begin{tabular}{|c|c|c|c|c|c|}
\hline \multirow{2}{*}{ FV } & \multirow{2}{*}{ GL } & \multicolumn{4}{|c|}{ Quadrado médio } \\
\hline & & $\mathrm{CB}^{(2)}$ & NR & $\mathrm{NF}^{(3)}$ & $\mathrm{CF}^{(3)}$ \\
\hline Espécie (E) & 2 & $0,0649 * *$ & $0,4977^{*}$ & $9,3973 \mathrm{~ns}$ & $1,6882^{* *}$ \\
\hline Meio (M) & 1 & $0,2672^{* *}$ & $0,6590^{*}$ & $306,7872^{* *}$ & $1,3754^{* *}$ \\
\hline Tipo do explante (TE) & 3 & $0,0200^{* *}$ & $0,5095^{*}$ & $16,2339^{*}$ & $0,2457^{*}$ \\
\hline $\mathrm{E} \times \mathrm{M}$ & 2 & $0,0442^{* *}$ & $0,9537^{* *}$ & $8,6975 \mathrm{~ns}$ & $0,4766^{* *}$ \\
\hline $\mathrm{E} \times \mathrm{TE}$ & 6 & $0,0396^{* *}$ & $0,0651 \mathrm{~ns}$ & $15,2359 * *$ & $0,2199 *$ \\
\hline $\mathrm{M} \times \mathrm{TE}$ & 3 & $0,0305^{* *}$ & $0,1561 \mathrm{~ns}$ & $13,7554^{*}$ & 0,2933* \\
\hline $\mathrm{E} \times \mathrm{M} \times \mathrm{TE}$ & 6 & $0,0114^{*}$ & $0,1035 \mathrm{~ns}$ & $5,4045 \mathrm{~ns}$ & $0,2206^{*}$ \\
\hline Erro a & $490(284)^{(1)}$ & 0,0043 & 0,1585 & 4,3903 & 0,0779 \\
\hline Avaliação (A) & 2 & $0,0997^{* *}$ & $1,3115^{* *}$ & $23,0254^{* *}$ & $0,3356^{* *}$ \\
\hline $\mathrm{E} \times \mathrm{A}$ & 4 & $0,0026^{* *}$ & $0,4662^{* *}$ & $18,7690^{* *}$ & $0,2953^{* *}$ \\
\hline $\mathrm{M} \times \mathrm{A}$ & 2 & $0,0136^{* *}$ & $0,2323^{* *}$ & $0,5658 \mathrm{~ns}$ & $0,1455^{* *}$ \\
\hline $\mathrm{TE} \times \mathrm{A}$ & 6 & $0,0005 \mathrm{~ns}$ & $0,0790 \mathrm{~ns}$ & $2,0969 \mathrm{~ns}$ & $0,1858^{* *}$ \\
\hline $\mathrm{E} \times \mathrm{M} \times \mathrm{A}$ & 4 & $0,0024^{* *}$ & $0,2044^{* *}$ & $13,5108^{* *}$ & $0,2347^{* *}$ \\
\hline $\mathrm{E} \times \mathrm{TE} \times \mathrm{A}$ & 12 & $0,0008 \mathrm{~ns}$ & $0,0692 \mathrm{~ns}$ & $1,3548 \mathrm{~ns}$ & $0,2312^{* *}$ \\
\hline $\mathrm{M} \times \mathrm{TE} \times \mathrm{A}$ & 6 & $0,0008 \mathrm{~ns}$ & $0,0643 \mathrm{~ns}$ & $2,3615 \mathrm{~ns}$ & $0,3391^{* *}$ \\
\hline $\mathrm{E} \times \mathrm{M} \times \mathrm{TE} \times \mathrm{A}$ & 12 & $0,0010 \mathrm{~ns}$ & $0,0488 \mathrm{~ns}$ & $2,5324 \mathrm{~ns}$ & $0,2548^{* *}$ \\
\hline Erro b & $940(267)^{(1)}$ & 0,0007 & 0,0445 & 1,826 & $0,0213^{* *}$ \\
\hline CV $(\%)$ & & 2,38 & 26,21 & 124,43 & 10,09 \\
\hline
\end{tabular}

** e *: significativo a $1 \%$ e $5 \%$ de probabilidade pelo teste de F respectivamente. ns: não signficativo. $\left({ }^{1}\right)$ relativo à variável CF. $\left({ }^{2}\right)$ transformado para $\ln (x+10) \cdot\left({ }^{3}\right)$ transformado para raiz $(x+0,5)$. 
Tabela 2. Valores médios para o comprimento das brotações, número de raízes e coloração das folhas em função dos meios de cultura e das espécies. P. edulis Sims f. edulis, P. giberti N. E. Brown e P. laurifolia L.

\begin{tabular}{|c|c|c|c|c|}
\hline \multirow{2}{*}{ Meio } & \multicolumn{3}{|c|}{ Espécie } & \multirow{2}{*}{ Média } \\
\hline & P. edulis & P. giberti & P. laurifolia & \\
\hline \multicolumn{5}{|c|}{ Comprimento das brotações $(\mathrm{cm})$} \\
\hline MS & $2,1109 \mathrm{aB}$ & 3,2008 aA & $1,9183 \mathrm{aB}$ & 2,4243 a \\
\hline $1 / 2 \mathrm{MS}$ & 1,7931 aA & $1,6532 \mathrm{bAB}$ & $1,3695 \mathrm{bB}$ & $1,6205 \mathrm{~b}$ \\
\hline Média & $1,9376 \mathrm{~B}$ & $2,4451 \mathrm{~A}$ & $1,6633 \mathrm{C}$ & \\
\hline \multicolumn{5}{|c|}{ Número de raízes } \\
\hline MS & $0,1931 \mathrm{bB}$ & $0,1565 \mathrm{aB}$ & $0,5097 \mathrm{aA}$ & 0,2891 a \\
\hline $1 / 2 \mathrm{MS}$ & 0,2419 aA & $0,1760 \mathrm{aA}$ & $0,1256 \mathrm{bA}$ & $0,1853 \mathrm{~b}$ \\
\hline Média & $0,2196 \mathrm{AB}$ & 0,17 B & $0,3320 \mathrm{~A}$ & \\
\hline \multicolumn{5}{|c|}{ Coloração das folhas } \\
\hline MS & $1,8592 \mathrm{aA}$ & $1,7442 \mathrm{bA}$ & $1,0903 \mathrm{bB}$ & $1,5222 \mathrm{~b}$ \\
\hline $1 / 2 \mathrm{MS}$ & $1,9667 \mathrm{aB}$ & $2,3810 \mathrm{aA}$ & $1,5067 \mathrm{aC}$ & 1,8945 a \\
\hline Média & $1,9084 \mathrm{~A}$ & $1,9531 \mathrm{~A}$ & $1,2261 \mathrm{~B}$ & - \\
\hline
\end{tabular}

Médias seguidas pela mesma letra minúscula nas colunas e maiúsculas nas linhas não diferem estatisticamente entre si pelo teste de Tukey a $5 \%$ de probabilidade.

Verificou-se melhor desenvolvimento do sistema radicular quando os explantes da espécie $P$. laurifolia L. foram cultivados em meio MS. Reduzindose a concentração dos sais do MS no meio de cultura, a espécie $P$. edulis f. edulis foi mais eficiente no processo da rizogênese, enquanto em $P$. giberti N. E. Brown houve um enraizamento similar para ambos os meios testados (Tabela 2). Esses dados reforçam a influência das espécies nas respostas in vitro, uma vez que cada espécie possui características únicas, determinadas por fatores genéticos, e portanto as condições para seu cultivo in vitro são diferenciadas.

Os valores médios para a coloração das folhas em função dos meios de cultura e das espécies (Tabela 2), revelam que apenas para $P$. edulis Sims f. edulis o meio não proporcionou diferença significativa. Para as demais espécies, o meio MS completo proporcionou melhor aspecto das microplantas. No meio MS completo a espécie $P$. laurifolia L. foi a que obteve valor mais próximo de 1 , significando que nesse meio foi observado maior número de folhas verdes. Para o meio $1 / 2$ MS, todas as espécies diferiram estatisticamente, sendo $P$. laurifolia $L$. a que obteve maior número de folhas verdes seguido por P. edulis Sims f. edulis e P. giberti N. E. Brown.

Além do meio de cultura, o tipo de explante também é um fator importante a ser considerado no estabelecimento do cultivo in vitro. Verificou-se que, para P. edulis Sims f. edulis, os segmentos nodais que continham a $2 .^{\text {a }}$ e $3 .^{\text {a }}$ gemas axilares tiveram maior comprimento das brotações (Tabela 3). Quanto à $P$. giberti N. E. Brown os segmentos nodais que continham a gema apical, 1. ${ }^{\mathrm{a}}$ e $2 .^{\mathrm{a}}$ gemas axilares não diferiram estatisticamente entre si, porém os segmentos nodais que continham a gema apical e a $1 .^{a}$ gema axilar foram superiores às demais posições. No entanto, não foi observada diferença significativa entre os tipos de explantes no crescimento das brotações para a espécie P. laurifolia L. Essas diferentes respostas possivelmente estão relacionadas com o nível endógeno dos diferentes reguladores de crescimento. A auxina, por exemplo, é um tipo de regulador vegetal produzido principalmente nos tecidos vegetais de órgãos aéreos, regiões apicais e transportada de célula a célula e chegam as raízes provavelmente através do floema (CASTRO e VIEIRA, 2001), formando, portanto, um gradiente de concentração ao longo do caule.

O número de folhas expandidas ao longo do período de cultivo e a coloração definem a qualidade das microplantas, podendo ser indicativos na escolha do tipo de meio e explante mais adequado para o estabelecimento in vitro. Na tabela 3, observa-se que o tipo de explante não influenciou o número de folhas para a espécie $P$. laurifolia $\mathrm{L}$. $(\mathrm{P} \leq 0,05)$. Na espécie $P$. edulis Sims f. edulis, nos segmentos nodais que continham a $2 .^{\text {a }}$ e $3 .^{a}$ gemas axilares, apesar de não diferirem significativamente dos segmentos nodais que continham a $1 .^{\mathrm{a}}$ gema axilar, verificou-se número de folhas superior aos que continham a gema apical. $\mathrm{Na}$ espécie $P$. giberti N. E. Brown os segmentos nodais que continham a $1 .^{a}$ gema axilar foram superiores aos demais. 
Tabela 3. Valores médios para o comprimento das brotações, número de folhas e coloração das folhas, em função dos tipos de explantes para as espécies. P. edulis Sims f. edulis, P. giberti N. E. Brown e P. laurifolia L.

\begin{tabular}{lccc}
\hline \multirow{2}{*}{ Posição } & \multicolumn{3}{c}{ Espécie } \\
\cline { 2 - 3 }
\end{tabular}

$\begin{array}{lc}\text { Gema apical } & 1,1601 \mathrm{cC} \\ \text { 1. }^{\text {a }} \text { gema axilar } & 1,7522 \mathrm{bcB} \\ \text { 2. }^{\text {a }} \text { gema axilar } & 2,6392 \mathrm{aA} \\ \text { 3. }^{\text {a }} \text { gema axilar } & 2,3543 \mathrm{abA} \\ \text { Média } & 1,9376 \mathrm{~B}\end{array}$

Gema apical

1. ${ }^{a}$ gema axilar

2. ${ }^{a}$ gema axilar

3. ' gema axilar

Média

Gema apical

1. gema axilar

2. ${ }^{\text {a }}$ gema axilar

3. ${ }^{a}$ gema axilar

Média

$0,6449 \mathrm{bA}$
$1,0074 \mathrm{abA}$
$1,4000 \mathrm{aA}$
$1,3217 \mathrm{aA}$
$1,0727 \mathrm{~A}$

1,8772 aA

1,7692 aA

1,9041 aA

2,0746 aA

$1,9084 \mathrm{~A}$

Comprimento das brotações $(\mathrm{cm})$

Médias seguidas pela mesma letra minúscula nas colunas e maiúsculas nas linhas não diferem estatisticamente entre si pelo teste de Tukey a $5 \%$ de probabilidade.

De acordo com a tabela 3, apenas na espécie $P$. laurifolia $L$. foi observada diferença estatística $(P \leq 0,05)$, sendo os segmentos nodais que continham a gema apical, $1 .^{\mathrm{a}}$ e $2 .^{\mathrm{a}}$ gemas axilares foram superiores aos que continham a $3 .^{a}$ gema axilar, com maior número de folhas verdes. Somente nos segmentos nodais que continham $3 .{ }^{a}$ gema axilar não houve diferença estatística entre as espécies. Nas outras posições de gemas, a espécie $P$. laurifolia L. obteve valores mais próximos de 1, o que significa maior número de folhas verdes.

Quanto à influência do meio de cultura no desenvolvimento dos explantes, em função dos tipos de explantes e dos meios de cultura, verifica-se que o maior comprimento das brotações foi obtido no meio MS, exceto para a gema apical. Dentre os explantes responsivos nesse meio os segmentos nodais que continham a $1 .^{\mathrm{a}} \mathrm{e}$ 2. ${ }^{a}$ gemas axilares destacaram-se em relação aos demais, diferentemente do observado para o meio $1 / 2 \mathrm{MS}$, onde não se observou diferença, independentemente da natureza do explante (Tabela 4).

Os valores médios para o número de folhas mostrados na tabela 4 mostram que para o meio $1 / 2 \mathrm{MS}$ não houve diferença em relação à posição da gema. Para o meio MS os segmentos nodais que continham a $1 .^{a}$ e $2 .^{a}$ gemas axilares foram estatisticamente superiores $(P \leq 0,05)$ aos demais.

Quanto aos valores médios para a coloração das folhas (Tabela 4), pode-se notar que o meio $1 / 2 \mathrm{MS}$ foi o único com diferença em relação à coloração de folhas ocasionada pelo tipo de explante; os segmentos nodais que continham a gema apical, $1 .^{\mathrm{a}}$ e $2 .^{\mathrm{a}}$ gemas axilares foram estatisticamente superiores aos que continham a $3 .^{\text {a }}$ gema axilar, com valores mais próximos de 1, ocasionando maior número de folhas verdes. Só houve diferença significativa entre os meios para os segmentos nodais que continham a gema apical e $3 .^{\text {a }}$ gema axilar. Em ambas, no meio MS completo foi observado maior número de folhas verdes.

No que se refere às diferentes épocas de avaliação, 45, 75 e 105 dias, verificou-se um comportamento crescente para o comprimento das brotações e número de raízes (Tabela 5). Dentro de cada época de avaliação a espécie $P$. giberti N. E. Brown obteve maior comprimento de brotações, exceto 
aos 75 dias em que se comportou semelhantemente a P. edulis Sims f. edulis. As espécies P. laurifolia L. e P. edulis Sims f. edulis obtiveram melhor resposta para o processo da rizogênese.

Com relação à qualidade da parte aérea, observou-se apenas na espécie $P$. giberti N. E. Brown decréscimo no número de folhas ao longo do período de avaliação (Tabela 5). Outro aspecto observado foi o incremento de folhas senescentes a partir da segunda avaliação. Resultados semelhantes foram obtidos por JuNGHANS et al. (2002) e GONÇALVES et al. (2003), também trabalhando com microplantas de P. edulis f. flavicarpa.

Em cultura de tecidos, a produção em excesso de etileno pode levar ao acúmulo do regulador nos frascos de cultura, dificultando o desenvolvimento dos explantes e a morfogênese in vitro, resultando na senescência das folhas (Trevisan, 2005). O maracujazeiro é uma espécie que produz alta taxa de etileno (LuDFord, 1995) e sua presença refletiu na taxa de regeneração in vitro do maracujazeiro amarelo (FARIA e SEgura,1997).

Independentemente do meio, verificou-se comportamento crescente para comprimento das brotações e número de raízes ao longo do período de avaliação (Tabela 6). Para comprimento das brotações o meio MS apresentou valores estatisticamente superiores. Para número de raízes foi observada superioridade do meio MS apenas na avaliação aos 150 dias. O meio MS completo foi o que proporcionou valores mais próximos de 1 , com folhas com coloração verde mais intenso, diferindo estatisticamente do meio com a metade de concentração de sais, independente da época de avaliação. Esses resultados estão de acordo com os obtidos por JunGHANs et al. (2002) que, trabalhando com microplantas de $P$. edulis f. flavicarpa comprovaram também que a maior percentagem de folhas verdes ocorreu no meio MS completo.

Tabela 4. Valores médios para o comprimento das brotações, número de folhas e coloração das folhas, em função dos tipos de explantes e meios de cultura para as espécies P. edulis Sims f. edulis, P. giberti N. E. Brown e P. laurifolia L.

\begin{tabular}{llcl}
\hline \multirow{2}{*}{ Posição } & \multicolumn{2}{c}{ Meio } & \\
\cline { 2 - 3 } & MS MS & Média
\end{tabular}

Comprimento das brotações $(\mathrm{cm})$

Gema apical

1. a gema axilar

2. gema axilar

3. ${ }^{a}$ gema axilar

Média

Gema apical

1. ${ }^{\mathrm{a}}$ gema axilar

2. ${ }^{a}$ gema axilar

3. ${ }^{\text {a }}$ gema axilar

Média

\section{Gema apical}

1. ${ }^{a}$ gema axilar

2. ${ }^{a}$ gema axilar

3. a gema axilar

Média
$1,9169 \mathrm{cA}$
2,6034 abA
2,9858 aA
2,2119 bcA
2,4243 A

$1,2347 \mathrm{bA}$
$1,8922 \mathrm{aA}$
$1,8525 \mathrm{aA}$
$1,1579 \mathrm{bA}$
$1,5479 \mathrm{~A}$

$1,4752 \mathrm{aB}$

1,5128 aA

1,5283 aA

$1,6102 \mathrm{aB}$

$1,5222 \mathrm{~B}$
1,7136 aA

$1,8150 \mathrm{~b}$

$1,5585 \mathrm{aB}$

$1,5859 \mathrm{aB}$

2,0797 ab

2,2839 a

$1,6150 \mathrm{aB}$

$1,9221 \mathrm{ab}$

1,6205 B

Número de folhas

$$
\begin{aligned}
& 0,5794 \mathrm{aB} \\
& 0,7366 \mathrm{aA} \\
& 0,5217 \mathrm{aB} \\
& 0,6483 \mathrm{aB}
\end{aligned}
$$

0,9063 b

1,3130 a

$1,1853 \mathrm{ab}$

$0,9091 \mathrm{~b}$

Coloração das folhas
$1,5964 \mathrm{~b}$

$1,5615 \mathrm{~b}$

$1,6149 \mathrm{~b}$

2,0283 a

Médias seguidas pela mesma letra minúscula nas colunas e maiúsculas nas linhas não diferem estatisticamente entre si pelo teste de Tukey a $5 \%$ de probabilidade. 
Tabela 5. Valores médios para o comprimento das brotações, número de raízes, número de folhas e coloração das folhas, em função das espécies $P$. edulis Sims f. edulis, P. giberti N. E. Brown e P. laurifolia L. e das épocas de avaliação

\begin{tabular}{|c|c|c|c|c|}
\hline \multirow{2}{*}{ Espécie } & \multicolumn{3}{|c|}{ Avaliação (dias) } & \multirow{2}{*}{ Média } \\
\hline & 45 & 75 & 105 & \\
\hline \multicolumn{5}{|c|}{ Comprimento das brotações $(\mathrm{cm})$} \\
\hline P. edulis & $1,3684 \mathrm{bC}$ & $2,1206 \mathrm{aB}$ & $2,3296 \mathrm{bA}$ & $1,9376 \mathrm{~b}$ \\
\hline P. giberti & $1,9191 \mathrm{aC}$ & $2,4942 \mathrm{aB}$ & $2,9395 \mathrm{aA}$ & $2,4451 \mathrm{a}$ \\
\hline P. laurifolia & $1,3114 \mathrm{bC}$ & $1,6345 \mathrm{bB}$ & $2,0478 \mathrm{cA}$ & $1,6633 \mathrm{c}$ \\
\hline Média & $1,5402 \mathrm{C}$ & 2,0892 B & $2,4465 \mathrm{~A}$ & - \\
\hline \multicolumn{5}{|c|}{ Número de raízes } \\
\hline P. edulis & $0,0760 \mathrm{aB}$ & $0,2353 \mathrm{abA}$ & $0,3491 \mathrm{bA}$ & $0,2196 \mathrm{ab}$ \\
\hline P. giberti & 0,1676 aA & $0,1395 \mathrm{bA}$ & 0,1916 cA & $0,1660 \mathrm{~b}$ \\
\hline P. laurifolia & $0,0503 \mathrm{aC}$ & $0,3072 \mathrm{aB}$ & $0,6433 \mathrm{aA}$ & $0,3320 \mathrm{a}$ \\
\hline Média & 0,0994 C & $0,2264 \mathrm{~B}$ & 0,3895 A & - \\
\hline \multicolumn{5}{|c|}{ Número de folhas } \\
\hline P. edulis & $0,5614 \mathrm{bB}$ & 1,2544 aA & $1,4083 \mathrm{aA}$ & $1,0727 \mathrm{a}$ \\
\hline P. giberti & $1,1214 \mathrm{aA}$ & 0,9942 aAB & $0,7964 \mathrm{bB}$ & $0,9727 \mathrm{a}$ \\
\hline P. laurifolia & $0,8344 \mathrm{abC}$ & $1,1758 \mathrm{aB}$ & $1,6561 \mathrm{aA}$ & $1,2213 \mathrm{a}$ \\
\hline Média & 0,8403 B & $1,1403 \mathrm{~A}$ & $1,2799 \mathrm{~A}$ & - \\
\hline \multicolumn{5}{|c|}{ Coloração das folhas } \\
\hline P.edulis & $1,7500 \mathrm{aB}$ & 1,9583 aA & $1,9608 \mathrm{aA}$ & $1,9084 \mathrm{a}$ \\
\hline P. giberti & $1,7037 \mathrm{aB}$ & $2,0000 \mathrm{aA}$ & $2,0488 \mathrm{aA}$ & $1,9531 \mathrm{a}$ \\
\hline P. laurifolia & $1,2963 \mathrm{bA}$ & $1,2716 \mathrm{bA}$ & $1,0882 \mathrm{bA}$ & $1,2261 \mathrm{~b}$ \\
\hline Média & 1,5291 B & $1,7342 \mathrm{~A}$ & $1,6967 \mathrm{~A}$ & - \\
\hline
\end{tabular}

Médias seguidas pela mesma letra minúscula nas colunas e maiúsculas nas linhas não diferem estatisticamente entre si pelo teste de Tukey a $5 \%$ de probabilidade.

Tabela 6. Valores médios para o comprimento das brotações, em cm, número de raízes e coloração das folhas em função dos meios de cultura e das épocas de avaliações

\begin{tabular}{|c|c|c|c|c|}
\hline \multirow{2}{*}{ Meio } & \multicolumn{3}{|c|}{ Avaliação (dias) } & \multirow{2}{*}{ Média } \\
\hline & 45 & 75 & 105 & \\
\hline \multicolumn{5}{|c|}{ Comprimento das brotações } \\
\hline MS & $1,7462 \mathrm{aC}$ & $2,5294 \mathrm{aB}$ & 3,0016 aA & $2,4243 \mathrm{a}$ \\
\hline $1 / 2 \mathrm{MS}$ & $1,3343 \mathrm{bC}$ & $1,6541 \mathrm{bB}$ & $1,8799 \mathrm{bA}$ & $1,6205 b$ \\
\hline Média & $1,5402 \mathrm{C}$ & $2,0892 \mathrm{~B}$ & $2,4465 \mathrm{~A}$ & - \\
\hline \multicolumn{5}{|c|}{ Número de raízes } \\
\hline MS & $0,1032 \mathrm{bC}$ & $0,2688 \mathrm{aB}$ & 0,4980 aA & $0,2891 \mathrm{a}$ \\
\hline $1 / 2 \mathrm{MS}$ & $0,0956 \mathrm{aB}$ & $0,1843 \mathrm{aAB}$ & $0,2787 \mathrm{bA}$ & $0,1853 \mathrm{~b}$ \\
\hline Média & $0,0994 \mathrm{C}$ & $0,2264 \mathrm{~B}$ & $0,3895 \mathrm{~A}$ & - \\
\hline \multicolumn{5}{|c|}{ Coloração das folhas } \\
\hline MS & $1,3365 \mathrm{bB}$ & $1,5948 \mathrm{bA}$ & $1,5873 \mathrm{bA}$ & $1,5222 b$ \\
\hline $1 / 2 \mathrm{MS}$ & $1,8235 \mathrm{aB}$ & $1,9881 \mathrm{aA}$ & 1,8588 aA & $1,8945 \mathrm{a}$ \\
\hline Média & 1,5291 B & $1,7342 \mathrm{~A}$ & $1,6967 \mathrm{~A}$ & - \\
\hline
\end{tabular}

Médias seguidas pela mesma letra minúscula nas colunas e maiúsculas nas linhas não diferem estatisticamente entre si pelo teste de Tukey a $5 \%$ de probabilidade. 


\section{CONCLUSÃO}

Nas condições em que o trabalho foi executado, o meio de cultura MS completo e a utilização de segmentos nodais contendo a segunda gema axilar propiciaram o melhor desenvolvimento in vitro para as espécies estudadas.

\section{REFERÊNCIAS}

CASTRO, P. R. C.; VIEIRA, E. L. Aplicações de reguladores vegetais na agricultura tropical. Guaíba - RS: Agropecuária, 2001. $132 \mathrm{p}$.

DORNELAS, M. C. Cultura e fusão de protoplastos de Passiflora spp. Piracicaba, 1995. 182 f. Dissertação (Mestrado em Agronomia) - Escola Superior de Agricultura "Luiz de Queiroz", Universidade de São Paulo, Piracicaba.

DORNELAS, M. C.; VIEIRA, M. L. C. Tissue culture studies on species of Passiflora. Plant Cell, tissue and Organ Culture, Dordreecht, v. 36, n. 2, p. 211-217, feb. 1994.

DREW, R. A. In vitro culture of adult and juvenile bud explants of Pasiflora species. Plant Cell, Tissue and Organ Culture, Dordrecht, v. 26, n. 1, p. 23-27, jul. 1991.

FARIA, J. L. C.; SEGURA, J. Micropropagation of yellow passionfruit by axillary bud proliferation. HortScience, Alexandria, v. 32, n. 7, p. 1276-1277, 1997.

FREITAS, I.M.N. Micropropagação in vitro de maracujazeiro. Atas de Horticultura. Vilamoura, v.18, p.103-106, 1997.

GONÇALVES, K. S.; JUNGHANS, T. G.; VIDAL, A. M. Cultivo in vitro de gemas laterais de maracujazeiro amarelo em função da temperatura. In. CONGRESSO BRASILEIRO DE MELHORAMENTO DE PLANTAS, 2., 2003. Melhoramento e Qualidade de Vida, Porto Seguro. 2003. (CD-ROM)

GILL, M. I. S.; CANCINO, G. O.; ANTHONY, P., DAVEY, M. R.; POWER, J. B.; LOWE, K. C. Pluronic F-68 Enhanced Shoot Regeneration in Micropropagated Citrus Rootstock and Passiflora Species. Acta Biotechnology, Weinheim, v. 23, n. 4, p. 349-358, 2003.

GRATTAPAGLIA, D.; MACHADO, M. A. Micropropagação. In: TORRES, A.C.; CALDAS, L. C.; BUSO, J. A. (Ed.) Cultura de tecidos e transformação genética de plantas. Brasília: EmbrapaCBAB, v.1, p. 183-260, 1998.

GUZZO, F.; CEOLDO, S.; ANDREETTA, F.; LEVI, M. In vitro culture from mature seeds of Passiflora species. Scientia Agrícola, Piracicaba, v.61, n.1, p. 108-113, jan/fev. 2004.

INSTITUTO BRASILEIRO DE GEOGRAFIA E ESTATÍSTICA IBGE. Banco de Dados Agregados: produção agrícola municipal. Brasília, 2001. Disponível em: http:// www.sidra.ibge.gov.br./bda. Acesso em: julho de 2006.
ISUTSA, D.K. Rapid micropropagation of passion fruit (Passiflora edulis Sims.) varieties. Scientia Horticulturae, v. 99, n.3, p. 395-400, fev. 2004.

JUNGHANS, T. G.; VIDAL, A. M.; SOUZA, A. S. Cultivo in vitro de ápices caulinares de maracujazeiro amarelo em função do meio de cultivo e temperatura In. XVII Congresso Brasileiro de Fruticultura: Os Novos Desafios da Fruticultura Brasileira, Belém. 2002. CD-ROM.

KANTHARAJAH, A. S.; DODD, W. A. In vitro micropropagation of Passiflora edulis (Purple passionfruit). Annals of Botany, Oxford, v. 65, n.3, p. 337-339, mar. 1990.

KAWATA, K.; USHIDA, C.; KAWAI, F.; KANAMORI, M.; KURIYAMA, A. Micropropagation of passion fruit from subcultured multiple shoot primordia. Journal of Plant Phisyology, Stuttgart, v. 147, p. 281-284, 1995.

LUDFORD, P.M. Postharvest hormone changes in vegetables and fruit. In: DAVIES, P.J. (Ed.) Plant hormones. Dordrecth: Kluwer, Academic Publishers, 1995. p. 725-750.

MONTEIRO-HARA, A. C. B. A. de. Cultivo in vitro de três espécies do gênero Passiflora. 2000, 82p. Dissertação (Mestrado) - Escola Superior de Agricultura "Luiz de Queiroz", Universidade de São Paulo, Piracicaba.

MORAN ROBLES, M. J. Multiplication vegetative, in vitro, des bourgeons axillaires de Passiflora edulis var. flavicarpa Degener et de P. mollissima Bailey. Fruits, Paris, v. 33, n.10, p. 693-699, 1978.

MURASHIGE, T.; SKOOG, F. A revised medium for rapid growth and bioassays with tobacco tissue cultures. Physiologia Plantarum, Copenhagen, v. 15, p. 473-497, 1962.

OTONI, W. C.; CASALI, V. W. D.; POWER, J. B.; DAVEY, M. R. Isolamento de protoplastos de mesófilo de P. suberosa L.: influência da idade das plantas matrizes. Revista Ceres, Viçosa, MG, v. 43, p. 157-164, 1996.

SAS INSTITUTE INC. SAS/STAT User's Guide. v. 8.0. Vol. I. Cary NC: SAS Institute, Inc., 2000.

SCORZA, R.; JANICK, J. In vitro flowering of Passiflora suberosa L. Journal of the American Society for Horticultural Science, Dordrecht, v. 105, p. 892-897, 1980.

TAKAHASHI, E. K. Transferência do gene atacina A para plantas de maracujá amarelo (Passiflora edulis Sims f. flavicarpa Deg.) por biobalística. 2002. 127p.Tese (Doutorado). Escola Superior de Agricultura Luiz de Queiroz, Piracicaba.

TREVISAN, F. Transformação genética do maracujazeiro (Passiflora edulis f. flavicarpa) para resistência ao vírus do endurecimento dos frutos. Dissertação (mestrado) - Escola Superior de Agricultura Luiz de Queiroz, 2005. 64p. 